\title{
HIGH RISK OF IMMUNE RECONSTITUTION INFLAMMATORY SYNDROME DEVELOPMENT AMONG PEOPLE LIVING WITH HIVIAIDS IN FAR-WESTERN REGION OF NEPAL
}

\author{
Mishra SK${ }^{1}$, Sharma $\mathbf{R}^{2}$, Mahat T ${ }^{3}$, Gupta BP 4 \\ ${ }^{1}$ National Public Health Labortory, Teku, Kathmandu, Nepal \\ 2 Department of Gynecology \& Obstretics, Janakpur Zonal Hospital, Nepal \\ ${ }^{3}$ Antiretroviral Therapy Centre, Pathology Department, Seti Zonal Hospital, Nepal \\ ${ }^{4}$ CPHD-Nepal, Kalimati Chowk, Kalimati, Kathmandu, Nepal
}

\begin{abstract}
Introduction: Absolute $\mathrm{CD} 4+$ cell counts and $\mathrm{CD} 4 / \mathrm{CD} 8$ ratio continue to be an important marker for clinical management of human immunodeficiency virus (HIV) infection and diagnosis of AIDS. CD4/ CD8 ratio has been also used for prediction of immune reconstitution inflammatory syndrome (IRIS). The objective of the study was to determine the immunological status in HIV infected people taking anti retroviral therapy (ART) on the basis of CD4+ level and to assess the risk of development of (IRIS) on the basis of $\mathrm{CD} 4+/ \mathrm{CD} 8+$ ratio.

Methodology: The study was carried out at Antiretroviral Therapy Centre of Seti Zonal Hospital (SZH), Dhangadi in Western region of Nepal; the second biggest ART center. The study included 760 HIV infected heterosexual, migrant laborer to India from Nepal and their spouses and children. CD profile was enumerated by FACS Count System.

Results: Out of 760, 33(5\%) had normal (between1-4) CD4/CD8 ratio, 727 (95\%) had abnormal ratio (less than1) of CD4/CD8. The chance of getting IRIS after ART treatment initiation in HIV infected people was $47 \%$ among which $30 \%$ found to be in high risk of getting IRIS (having CD+/CD8+ ratio less than 0.15 ) and $17 \%$ had chance of immune reconstitution inflammatory syndrome (IRIS) in future course of treatment (having $C D+/ C D 8+$ ratio between $0.15-0.30$ ).

Conclusion: The study provides the first baseline data on CD4, CD8, and CD4+/CD8+ ratio in HIV infected people in far-western region of Nepal and will sensitize the clinician about the risk of developing IRIS during ART treatment. Furthermore no test is currently available to establish a IRIS diagnosis. Standardized disease-specific clinical criteria for common infectious manifestations of the disease should be developed.
\end{abstract}

Key words: IRIS, CD4, HIV, Nepal

\section{INTRODUCTION}

Absolute CD4+ cell counts and CD4/CD8 ratio continue to be an important marker for clinical management of human immunodeficiency virus (HIV) infection and diagnosis of AIDS. CD4/CD8

\footnotetext{
Correspondence:

Mr. Shravan Kumar Mishra

National Public Health Laboratory, Teku

Kathmandu, Nepal

E-mail: shravanmishra11@yahoo.com
}

ratio has been also used for prediction of immune reconstitution inflammatory syndrome (IRIS). ${ }^{1}$ The development of IRIS in HIV-infected patients initiating antiretroviral therapy (ART) results from restored immunity to specific infectious or noninfectious antigens. A paradoxical clinical worsening of a known condition or the appearance of a new condition after initiating therapy characterizes the syndrome. Potential mechanisms for the syndrome include a partial recovery of the immune system or exuberant host immunological responses to antigenic stimuli. Despite numerous descriptions 
of the infectious and noninfectious causes of IRIS, the overall incidence of IRIS is unknown, but is dependent on the population studied and its underlying opportunistic infections burden. The infectious pathogens most frequently implicated in the syndrome are Mycobacteria, Varicella zoster virus, Herpesviruses, and Cytomegalovirus (CMV). ${ }^{1}$ In Nepal, the estimated number of people living with HIV is over 75,000 and as of 12 April 2008, 11,234 HIV cases were reported by official data of National center for AIDS and STD control (NCASC). ${ }^{2}$ Studies to date are often retrospective and focus on specific manifestations of IRIS, such as tuberculosis-associated IRIS (TB-IRIS). In a large retrospective analysis examining all forms of IRIS, $33 / 132(25 \%)$ of patients exhibited one or more disease episodes after initiation of $\mathrm{ART}^{3}{ }^{3}$ Other cohort analyses examining all manifestations of IRIS estimate that $17-23 \%$ of patients initiating ART will develop the syndrome.$^{4-6}$ Another large retrospective study reported $32 \%$ of patients with M. tuberculosis, M. avium complex, or Cryptococcus neoformans co-infection developed IRIS after initiating ART. Risk factors identified for the development of IRIS in one cohort included male sex, a shorter interval between initiating treatment for Ol and starting ART, a rapid fall in HIV-1 RNA after ART, and being ART-naïve at the time of OI diagnosis. ${ }^{7}$ Other significant predictors have also included younger age, male sex, a lower baseline CD4 cell percentage, a lower CD4 cell count at ART initiation, and a lower CD4 to CD8 cell ratio at baseline.,4 Since cohorts differ substantially in study populations and the type of IRIS (i.e. TB-IRIS only) examined varies conclusions regarding risk factors for IRIS become difficult. In these patients, clinical deterioration occurs despite increased CD4+ T lymphocyte counts and decreased plasma HIV-1 viral loads. ${ }^{3}$ Case reports of some patients initiating ART describe unique symptoms during immune system recovery thus expanding the clinical spectrum of the syndrome. Because clinical deterioration occurs during immune recovery, this phenomenon has been described as immune restoration disease (IRD), immune reconstitution syndrome (IRS), and paradoxical reactions. Given the role of the host inflammatory response in this syndrome, the term immune reconstitution inflammatory syndrome (IRIS) has been proposed and has become the most widely used and accepted term to describe the clinical entity.

The $C D 4 / C D 8$ ratio is a reflection of immune system health. A normal ratio is between 1 and 4. People without HIV infection generally have a greater number of CD4 cells than they have of CD8 cells. As people get older, the immune system defense against pathogens is weaker and the CD4/CD8 ratio tends to decrease. People with autoimmune diseases tend to have an increased CD4/CD8 ratio, while those with viral infections have a decreased ratio. Within six months of HIV seroconversion, the CD4 count generally decreases about $30 \%$ and the CD8 count may increase by about $40 \%$, resulting in an inverted ratio that is generally less than 1 . With antiretroviral treatment, the ratio may revert toward normal. Long-term non-progressors and those who start antiretroviral treatment early on generally have a normal CD4/CD8 ratio. Factors affecting CD4 count and subsequently the CD4/ CD8 ratio are some viral infections, tuberculosis, corticosteroid use, seasonal/diurnal variations, and variations in $\mathrm{CD} 4$ analyses.

Although not too much attention is paid to ratios now, one study found that the only independent predictors for immune reconstitution inflammatory syndrome (IRIS) were a low baseline CD4 count and a low CD4/CD8 ratio. People with a CD4/CD8 ratio of less than 0.15 were more likely to have an IRIS event than were people with a ratio greater than $0.30 .^{8}$

To date, no prospective therapeutic trials concerning the management of IRIS have been conducted. All evidence regarding the management of IRIS in the literature relates to case reports and small case series reporting on management practice. This does not provide reliable evidence regarding either the safety or efficacy of these approaches, but merely guidance regarding the practice of others in managing this difficult condition. In severe cases where the discontinuation of ART is a possibility, the potential disadvantages of therapy cessation, such as the development of viral resistance or AIDS progression, should be considered. 


\section{METHODOLOGY}

A descriptive study was carried out at ART centre of Seti Zonal Hospital (SZH), Dhangadi in Western region of Nepal; the second biggest ART center. After taking informed consent, information regarding age, sex, mode of transmission was recorded in the register. HIV was diagnosed by Tri dot method. This research was a routine part of Hospital program, funded by Family Health International (FHI). All the information obtained from Laboratory reports, hospital records and direct communication with patients were entered into SPSS program software and analyzed to obtain cluster differential profiles of the patients. The study included $760 \mathrm{HIV}$ infected heterosexual and migrant laborer to India from Nepal and their spouse and children. FACS Count System was used cell count. The study was conducted from December 2006 to November 2007. The ethical aspect was taken care by keeping anonymity of the individual and taken approval from institutional ethical committee. The data was analyzed using SPSS software.

\section{RESULTS}

The majority of the study subjects $(75 \%)$ were between $26-45$ years and $65 \%$ were females. There were $9 \%$ children and $6 \%$ over 46 years. The 32\% HIV infected people having CD4 count less than $200 \mathrm{cell} / \mathrm{ml}$ were on ART treatment, $45 \%$ were found with borderline levels (CD4 count between 200-500 cells/ml) and may need ART in near future and $9 \%$ of HIV infected people had CD4 counts within the normal range. Out of 760 , $33(5 \%)$ had normal (between1 - 4) CD4/CD8 ratio, $95 \%$ had abnormal ratio(less than 1 ) of CD4/CD8. The chance of getting IRIS after ART treatment initiation in HIV infected people was $47 \%$ among which $30 \%$ were at a higher risk of getting IRIS (having $C D+/ C D 8+$ ratio less than 0.15 ) and $17 \%$ had chance of developing IRIS in future with the initiation of treatment (having $\mathrm{CD}+/ \mathrm{CD} 8+$ ratio between 0.15-0.30).
Table 1. Gender wise distribution of people infected with HIVIAIDS in Far Western Region of Nepal

\begin{tabular}{|l|l|l|}
\hline Gender & Frequency & Percent \\
\hline Female & 492 & 65 \\
\hline Male & 268 & 35 \\
\hline Total & 760 & 100 \\
\hline
\end{tabular}

Table 2. Age group of people infected with HIV/AIDS in far western region of Nepal

\begin{tabular}{|l|l|l|}
\hline Age Group (Years) & Frequency & Percent \\
\hline Children ( below 14) & 70 & 9 \\
\hline $15-25$ & 82 & 11 \\
\hline $26-35$ & 347 & 45 \\
\hline $36-45$ & 217 & 29 \\
\hline$>46$ & 44 & 6 \\
\hline Total & 760 & 100 \\
\hline
\end{tabular}

Table 3. CD4+ count of people infected with HIVI AIDS in Far Western Region of Nepal

\begin{tabular}{|l|c|c|}
\hline \multicolumn{1}{|c|}{ CD4+ count } & Frequency & Percent \\
\hline$<200$ & 245 & 32 \\
\hline $200-500$ & 347 & 45 \\
\hline $501-750$ & 108 & 14 \\
\hline $751-1000$ & 34 & 5 \\
\hline$>1000$ & 26 & 4 \\
\hline Total & 760 & 100 \\
\hline
\end{tabular}

Table 4. Ratio of CD4/CD8 status in people infected with HIVIAIDS in far western region of Nepal.

\begin{tabular}{|l|c|c|}
\hline Ratio of CD4/CD4 & Frequency & Percent \\
\hline Between 1-4 & 33 & 5 \\
\hline Less than 1 & 727 & 95 \\
\hline Total & 760 & 100 \\
\hline
\end{tabular}

Table 5. CD4+/CD8+ ratio of people infected with HIVIAIDS in far western region of Nepal

\begin{tabular}{|l|c|c|}
\hline CD4+/CD8+ ratio & Frequency & Percentage \\
\hline Less than 0.15 & 126 & 17 \\
\hline Between $0.15-0.30$ & 230 & 30 \\
\hline More than 0.30 & 404 & 53 \\
\hline Total & 760 & 100 \\
\hline
\end{tabular}




\section{DISCUSSION}

The study sample showed a female preponderance (two-third) among people infected with HIV. Most of the infected population belonged to age group (15-45), along with children. One third of population were in acute need of ART therapy according to the past WHO recommendation (CD4 count $<200$ ) and this proportion would increase further if newWHO guidelines (CD4 count $<350$ ) were adopted. Out of $760,33(5 \%)$ had normal (between1 - 4) CD4/CD8 ratio, $95 \%$ had abnormal ratio (less than 1 ) of CD4/ CD8. This study has thrown light on the extent of the problem of IRIS in Nepalese HIV infected people with $47 \%$ having the chance of getting IRIS after ART treatment initiation. Further, among which $30 \%$ were at a higher risk of getting IRIS (having $C D+/ C D 8+$ ratio less than 0.15 ) and $17 \%$ had chance of immune reconstitution inflammatory syndrome (IRIS) in future course of treatment (having $\mathrm{CD}+/ \mathrm{CD} 8+$ ratio between $0.15-0.30$ ).

Florence E. et al. identified several risk factors for the development of IRIS, including younger age at initiation of HAART, lower baseline CD4 cell percentage or CD4:CD8 ratio, and, to a lesser extent, higher baseline CD8 cell percentage. Older age has been identified as a risk factor for a suboptimal CD4 cell response and discordant CD4 cell and virological responses to HAART. ${ }^{9}$ As a result, younger age at initiation of HAART is likely to result in greater immune restoration and, therefore, an increased risk of developing IRIS., ${ }^{9,10}$

Breton F. et al and Martinez E. et al. in two recent studies of patients with predominantly mycobacterial disease ${ }^{11,12}$ found that IRIS was associated with a higher CD4 cell percentage and $\mathrm{CD} 4 \%: \mathrm{CD} 8 \%$ ratio and a more marked and persistent reduction in viral load. ${ }^{12}$ This disparity in findings may be explained by differences in the relative frequency of various IRIS events across studies and in the frequency of CD4 cell count and viral load monitoring, whereby the reported CD4 cell counts at event or at 12 weeks after HAART initiation were often based on CD4 cell counts up to 8 weeks before or after this time point. Resolution of this can only be achieved by undertaking large prospective studies with $T$ cell subset measurement at baseline and monthly for at least 6 months. They found that a higher CD8 cell percentage $(>65 \%)$ at baseline and at 12 weeks (as well as a lower CD4:CD8 ratio) was associated with 3-fold increase in risk of IRIS, although this was no longer significant after adjustment for CD4 cell percentage. But, in another study of mycobacterial IRIS, there was no such association with IRIS. ${ }^{56}$ This suggests that the pathogenic mechanisms associated with IRIS may differ according to the type of pathogen. In contrast, an enhanced CD8+ cytotoxic T lymphocyte response may be more important in the immunopathogenesis of IRIS to viral infections, such as Herpes zoster, ${ }^{13,14}$ Cytomegalovirus, Hepatitis C, or Human herpesvirus $8,{ }^{15}$ although natural killer cells may also be implicated. ${ }^{16}$ More recently, distinct polymorphisms in certain major histocompatibility complex or cytokine genes in association with mycobacterial and herpesvirusassociated IRIS have been described, ${ }^{17-20}$ which indicates a genetic susceptibility to IRIS.

\section{CONCLUSIONS}

The study provides the first baseline data on CD4, $\mathrm{CD} 8$, and $\mathrm{CD} 4+/ \mathrm{CD} 8+$ ratio in HIV infected people in western region of Nepal and will sensitize the clinician of the risk of developing IRIS during ART treatment based on CD4/CD8 ratio. While exact estimates of incidence are not yet available, IRIS in patients initiating ART has been firmly established as a significant problem in both high and low income countries. Because of wide variation in clinical presentation and the widening spectrum of symptoms and etiologies reported, diagnosis remains problematic. Furthermore no test is currently available to establish an IRIS diagnosis. Standardized disease-specific clinical criteria for common infectious manifestations of the disease should be developed to: 1) identify risk factors for developing the syndrome and 2) optimize the prevention, management of opportunistic infections. Results of trials addressing the optimal timing and duration of treatment of opportunistic infections will assist in developing guidelines for the prevention and management of IRIS. Treatment of IRIS will remain a clinical challenge due to the variety of clinical presentations and the presence of multiple pathogens capable of causing the syndrome. 
Until a greater understanding of the syndrome is achieved in different regions of the world, clinicians need to remain vigilant when initiating ART and individualize therapy according to known treatment options for the specific infectious agent. Patients at greatest risk for the development of serious IRIS events with a low $C D 4: C D 8$ ratio of $\angle 0.15$, should be screened to exclude an active or subclinical infection with important opportunistic pathogens.

\section{REFERENCES}

1. David M Murdoch, Willem DF Venter, Annelies Van Rie and Charles Feldman. Immune reconstitution inflammatory syndrome (IRIS): review of common infectious manifestations and treatment options. AIDS Research and Therapy 2007;4:9

2. National Centre for AIDS and STI control (NCASC). Cumulative HIVIAIDS Situation of Nepal. Fact sheet updated on 12 April, 2008.

3. French MA, Lenzo $\mathrm{N}$, John $\mathrm{M}$, et al. Immune restoration disease after the treatment of immunodeficient HIV-infected patients with highly active antiretroviral therapy. HIV Med 2000;1:10715.

4. Ratnam I, Chiu C, Kandala NB, Easterbrook PJ. Incidence and risk factors for immune reconstitution inflammatory syndrome in an ethnically diverse HIV type 1-infected cohort. Clin Infect Dis 2006;42:41827.

5. Jevtovic DJ, Salemovic D, Ranin J, Pesic I, Zerjav $S$, Djurkovic-Djakovic $O$. The prevalence and risk of immune restoration disease in HIV-infected patients treated with highly active antiretroviral therapy. HIV Med 2005;6:140-43.

6. Puthanakit $\mathrm{T}$, Oberdorfer $\mathrm{P}, \mathrm{Akarath} u \mathrm{~N} \mathrm{~N}$, Wannarit $P$, Sirisanthana $T$, Sirisanthana V. Immune reconstitution syndrome after highly active antiretroviral therapy in human immunodeficiency virus-infected thai children. Pediatr Infect Dis J 2006;25:53-58.

7. Shelburne $\mathrm{SA}$, Visnegarwala $\mathrm{F}$, Darcourt $J$ et al. Incidence and risk factors for immune reconstitution inflammatory syndrome during highly active antiretroviral therapy. Aids 2005;19:399-406.
8. http://www.aidsmap.com/CD4CD8-ratio

9. Florence E, Lundgren J, Dreezen C, et al. Factors associated with a reduced CD4 lymphocyte count response to HAART despite full viral suppression in the EuroSIDA study. HIV Med 2003;4:255-62.

10. Douek DC, McFarland RD, Keiser PH, et al. Changes in thymic function with age and during the treatment of HIV infection. Nature 1998;396:690-5.

11. Shelburne SA, Visnegarwak F, Darcourt J et al. Incidence and risk factors for immune reconstitution syndrome during highly active antiretroviral therapy. AIDS 2005;19:399-406.

12. Breton $F$, Duval $X$, Estellat $C$, et al. Determinants of immune reconstitution syndrome in HIV type 1infected patients with tuberculosis after initiation of antiretroviral therapy. Clin Infect Dis 2004;39:170912.

13. Martinez E, Gatell J, Yolanda M, et al. High incidence of herpes zoster in patients with AIDS soon after therapy with protease inhibitors. Clin Infect Dis 1998;27:1510-3.

14. Domingo P, Torres $\mathrm{OH}$, Ris J, Vazquez G. Herpes zoster as an immune reconstitution disease after initiation of combination antiretroviral therapy in patients with human immunodeficiency virus type1 infection. Am J Med 2001;110:605-9.

15. Carr A, Emery S, Kelleher A, Law M, Cooper DA. CD8+ lymphocyte responses to antiretroviral therapy of HIV infection. J Acquir Immune Defic Syndr Hum Retrovirol 1996;13:320-6.

16. Clark BM, Krueger RG, Price P, French MAH. Compartmentalisation of the immune response in varicella zoster virus immune restoration disease causing transverse myelitis. AIDS 2004;18:121821.

17. Price P, Keane NM, Stone SF, Cheong KYM, French MA. MHC haplotypes affect the expression of opportunistic infection in HIV patients. Hum Immunol 2001;62:157-64.

18. Price P, Morahan $G$, Huang D, et al. Polymorphisms in cytokine genes define subpopulations of HIV1 patients who experience immune restoration diseases. AIDS 2002;16:2043-7. 
19. Stone SF, Price P, Brochier J, French MA. Plasma bioavailable interleukin-6 is elevated in human immunodeficiency virus-infected patients who experience herpesvirus-associated immune restoration disease after start of highly active antiretroviral therapy. J Infect Dis 2001;184:1073-7.
20. Hardy GAD, Imami N, Sullivan AP, et al. Reconstitution of CD4 T cell responses in HIV1 infected individuals initiating highly active antiretroviral therapy (HAART) is associated with renewed interleukin-2 production and responsiveness. Clin Exp Immunol 2003;134:98-100. 